DEMOGRAPHIC RESEARCH

VOLUME 36, ARTICLE 44, PAGES 1337-1360 PUBLISHED 26 APRIL 2017

http://www.demographic-research.org/Volumes/Vol36/44/

DOI: $10.4054 /$ DemRes.2017.36.44

Research Article

\title{
Spatial modelling of rural infant mortality and occupation in 19th century Britain
}

\section{Paul Atkinson Brian Francis}

Ian Gregory

Catherine Porter

\footnotetext{
This publication is part of the Special Collection on "Spatial analysis in historical demography: Micro and macro approaches," organized by Guest Editors Martin Dribe, Diego Ramiro Fariñas, and Don Lafreniere.

(C) 2017 Atkinson, Francis, Gregory \& Porter.

This open-access work is published under the terms of the Creative Commons Attribution NonCommercial License 2.0 Germany, which permits use, reproduction \& distribution in any medium for non-commercial purposes, provided the original author(s) and source are given credit. See http:// creativecommons.org/licenses/by-nc/2.0/de/
} 


\section{Contents}

1 Background $\quad 1338$

2 Patterns of rural IMR 1340

3 Occupation 1347

4 Conclusion 1355

$5 \quad$ Acknowledgements 1355

References 1356 


\title{
Spatial modelling of rural infant mortality and occupation in $19^{\text {th }}$ century Britain
}

\author{
Paul Atkinson ${ }^{1}$ \\ Brian Francis $^{2}$ \\ Ian Gregory ${ }^{3}$ \\ Catherine Porter ${ }^{4}$
}

\begin{abstract}
BACKGROUND

Infant mortality in $19^{\text {th }}$ century rural places has been largely neglected: to study it offers new insight into rural demography.

\section{OBJECTIVE}

This study examines infant mortality, and census occupations, between 1851 and 1911 across all the rural Registration Districts (RDs) of England and Wales.

METHODS

The decadal 1850s-1900s RD-level demographic data in the GB Historical GIS (GBHGIS) is analysed using latent trajectory analysis to identify clusters of RDs whose infant mortality rate (IMR) trajectories are most similar: these are mapped in ArcGIS. The recently published Integrated Census Microdata (I-CeM) resource is then used to study relationships between IMR and census-reported occupation. Geographically Weighted Regression is employed to explore spatial variation in the coefficient with which occupation affected IMR.
\end{abstract}

\section{RESULTS}

The study describes a previously unreported pattern of mortality variation, identifying seven groups of RDs with distinctive trajectories of infant mortality. A spatially varying link between IMR and female occupation rates in agriculture is noted.

\footnotetext{
${ }^{1}$ Lancaster University, UK. E-Mail: paul.atkinson4562@gmail.com.

${ }^{2}$ Lancaster University, UK.

${ }^{3}$ Lancaster University, UK.

${ }^{4}$ Lancaster University, UK.
} 


\section{CONCLUSIONS}

Spatial variation in rural social structures had demographic consequences. The decline in female agricultural occupation may have removed a source of harm to infant lives in the arable economy of the south and east, but simultaneously a source of benefit in the upland, pastoral north and west.

\section{CONTRIBUTION}

Findings about the costs and benefits of female agricultural employment can help explain the different trajectories of infant mortality in different regions, suggesting that female occupation and the details of what work women did could be a strong influence, positive or negative, on infant mortality.

\section{Background}

The $19^{\text {th }}$ century decline in infant mortality in rural England and Wales was already under way when the first large-scale official records began in the 1850s (Williams and Galley 1995; Gregory 2008): a much earlier start than in urban areas, where decline generally failed to set in before 1900. British scholarship has focussed on describing and interpreting the urban infant mortality rate (IMR), with occasional forays into the nature of urban-rural differences (Woods, Watterson, and Woodward 1989; Lee 1991; Williams and Galley 1995). Nor have other countries, with the exception of Sweden (Brandström, Edvinsson, and Rogers 2000; Edvinsso, Garðarsdóttir, and Thorvaldsen 2008; Bengtsson and Dribe 2010), been examined more thoroughly. Very little has been published - outside the Swedish literature - about variation in IMR between rural places (Woods and Hinde 1987; Woods and Shelton 1997; Sneddon 2006; Gregory 2008). This is surprising, because the evolution of England and Wales' rural IMR in the second half of the 19th century shows a clear and unexpected pattern, with potential implications for our understanding of other countries. We examine more covariates of IMR in a forthcoming Economic History Review article.

The scholarly neglect of rural infant mortality is a missed opportunity. Not only did rural people (on the definition of 'rural' adopted below) make up 47\% of English and Welsh society in 1861 , and still $22 \%$ in 1911 , but rural infant mortality also matters because studying rural places is an effective way of examining the longer-term infant mortality decline, which is masked in national aggregates by the penalty imposed by urbanization. This longer-term trend could simply be studied by extracting nondiarrhoea mortality (Millward and Bell 2001), since the 'urban penalty' was chiefly the result of sanitation that was inadequate for dense populations and was visible above all in infant mortality from diarrhoea (Szreter and Hardy 2000; Millward and Bell 
2001). However, as Williams and Galley (1995) have shown, diarrhoea was not the only cause of death to impose an urban penalty. It follows that analysis of rural places can avoid confounding influences other than that of urban diarrhoea mortality.

The infant mortality data used here is derived from the tables in the RegistrarGeneral's Decennial Supplements for each decade from the 1850s to the 1900s, "the best quality historical dataset available for the study of pre-twentieth-century national mortality patterns" (Szreter 1991: 438). This source provides decennial counts of births, and of deaths by age, assembled into a database by David Gatley (1997) and others. Geographical units of analysis available are regions, counties, and Registration Districts (RDs). The latter were a sub-county division based on Poor Law Unions: in the countryside they usually represented the area dependent on one market town. England and Wales were divided into around 630 of them. As the typical Victorian county combined large towns and rural areas, RDs have often been selected for units of study as they were more homogeneous. We follow this approach. The data is most easily accessible via the GB Historical Geographical Information System (GIS) (Southall, Gilbert, and Gregory 1998; Gregory et al. 2002).

The goal of the study is to examine rural places only, defined by population density, and to confine the analysis to places which remained rural throughout the period 1851-1911. For a criterion of 'rural' we followed Gregory's approach of ranking RDs by population density into eight classes, whose boundaries were created using nested means of the populations of all RDs in all six decades, to avoid imposing our own preconceptions of the 'rural' (Gregory 2008). The two lowest classes form our rural RDs, and have a population density below 183 persons per square kilometre. To be included in the study, a RD had to remain below this threshold throughout the period. (We also excluded 37 RDs for which the patchiness of data was a problem.) Our study therefore covered 363 RDs.

Although "there is no agreed area which can be seen as rural" (Short 2000: 1236), our proportion of the population treated as rural accords quite closely with the views of other, including contemporary scholars, and with contemporary labelling of places as towns and as urban or rural districts (Short 2000). For comparison, using an arbitrary population density of 100 persons per square kilometre, Woods, Watterson, and Woodward (1989) produced a set of 320 rural RDs. We note that analysis at RD level does not fully escape the problem of non-homogeneity noted earlier in relation to counties (all rural RDs had at least one town, sometimes quite large), but for a study of a whole country the RD is a good compromise between accuracy and complexity. 


\section{Patterns of rural IMR}

We begin by describing the patterns in the rural IMR data. This data is rich and complex, and the spatial evolution of IMR over time merits careful description before analysis of possible explanatory variables can begin. Table 1 presents the most basic rural data, aggregated into the ten relevant 1851 Census regions. It is clear that the most peripheral areas in the north and west (census regions 'Northern' and 'Wales') were the most resistant to change. However, these census regions were arbitrary bureaucratic assemblages of counties, with a very high-level aggregation, and of limited use in analysis. They serve here as a summary only. Figure 1 helps readers locate these regions geographically.

Table 1: Infant mortality rate in rural registration districts by region, 1851-1911

\begin{tabular}{ccccc}
\hline & $\mathbf{1 8 5 0 s}$ & \multicolumn{3}{c}{$\mathbf{1 9 0 0 s}$} \\
\hline South and East & $\mathbf{1 3 8}$ & 118 & $\mathbf{9 5}$ & 84 \\
South Eastern & & 149 & & 91 \\
South Midland & & 143 & & 90 \\
Eastern & & 130 & & 98 \\
West Midlands & 144 & $\mathbf{1 0 3}$ & 110 \\
North Midlands & $\mathbf{1 2 3}$ & & & 88 \\
South Western & & 118 & & 106 \\
North Western & & 163 & 108 \\
Yorkshire & & 143 & & 115 \\
Northern & & 113 & $\mathbf{9 8}$ & \\
Wales & $\mathbf{1 3 1}$ & & & \\
\hline
\end{tabular}

Source: Calculated from GBHGIS.

Note: All figures are weighted averages for rural RDs. Rows are 1851 Census regions (Wales includes Monmouth; there were no rural RDs in census region London.) 
Figure 1: Location of 1851 census regions

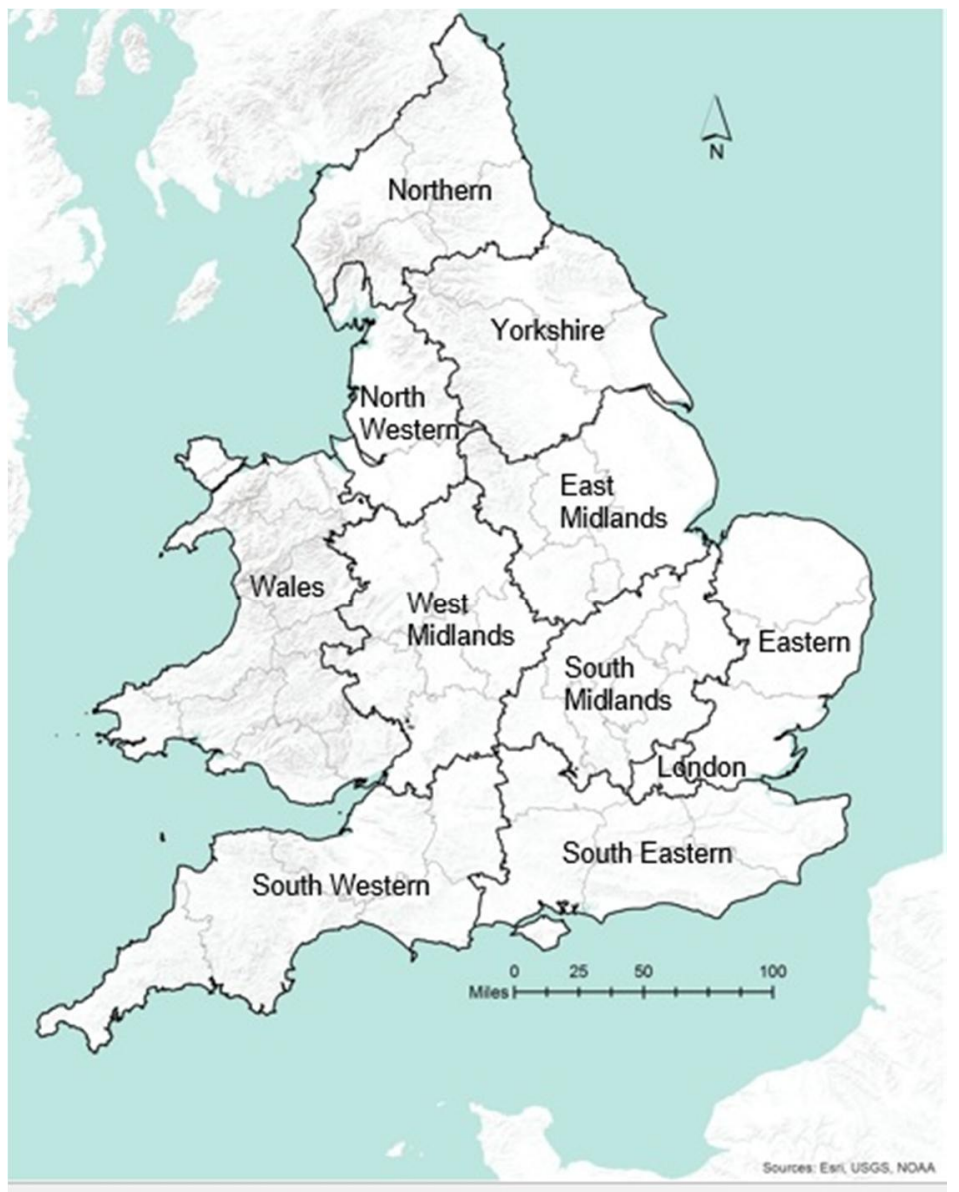

More insight is obtained by mapping change at Registration District level, and for this Figure 2 subtracts 1850s decadal IMR from the values for the 1900s. Woods and Shelton also mapped IMR, including cause of death, though they did not include a map of change over time, which draws out these patterns most clearly (Woods and Shelton 1997). Behind the mapped values of the change in IMR is a pattern of 1850s starting points, in which the lowest rural IMRs were found in parts of the peripheral census regions South Western, North Western, Northern, and Wales, with another group in the districts a few miles behind the south coast of South Eastern. As for IMR decline by the 1900s, Figure 2 shows that this was most rapid in a wide arc extending north-eastwards 
from the last-mentioned region near the south coast, up to the east coast, mostly within census regions South Eastern, South Midland, and Eastern. In the last named region we see the disappearance of the so-called Fenland penalty, discussed by Sneddon and more recently by Hinde and Fairhurst (Sneddon 2006; Hinde and Fairhurst 2015). ${ }^{5}$

\section{Figure 2: Change in IMR from the 1850s to 1900s (infant deaths per thousand live births)}

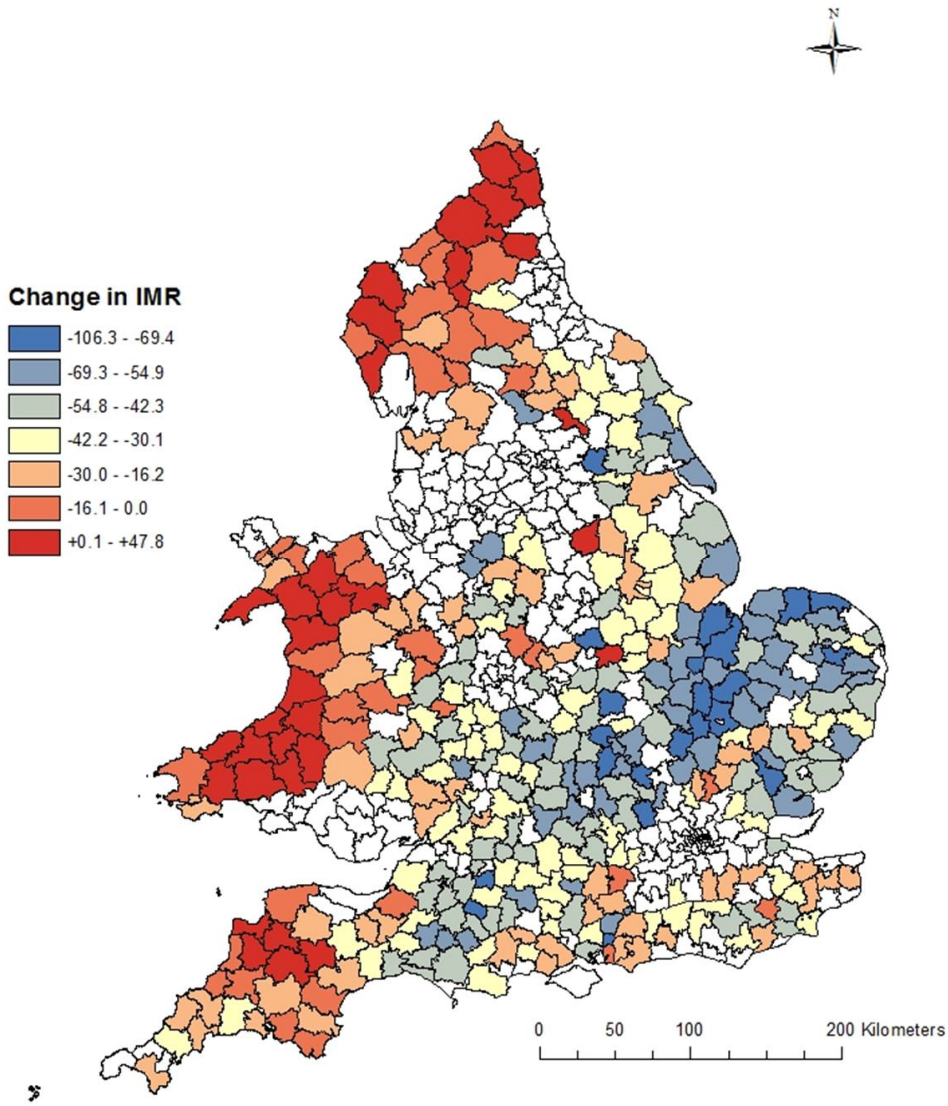

\footnotetext{
${ }^{5}$ Even before land drainage accelerated in the 19th century, much of the zone was not true fen terrain subject to the malaria described by Mary Dobson (1997).
} 
To analyse the IMR patterns further we used latent trajectory analysis, a longitudinal model-based clustering method to identify the statistical clusters into which the rural RDs fell, based on having similar IMR trajectories across the period (Nagin 1999; Sturgis and Sullivan 2008; Perelli-Harris and Lyons-Amos 2015). Our analysis assumes normally distributed trajectories and fits them into clusters by cubic polynomial. The technique presents solutions with any number of clusters. The optimum number is a trade-off between the Bayesian Information Criterion (BIC), a measure of the heterogeneity of the cluster, and ease of visualisation and analysis. There are diminishing analytical returns to increasing the number of classes. The BICs for different numbers of clusters led us to select a seven-class model. A six-class model provides very similar results but slightly less fine-grained distinctions. Table 2 gives descriptive statistics on the seven clusters.

Table 2: Characteristics of the seven latent clusters

\begin{tabular}{lrcc}
\hline Cluster & N & Mean* $^{*}$ IMR 1850s & Mean* IMR 1900s $^{*}$ \\
\hline A & 44 & 163 & 118 \\
B & 48 & 147 & 86 \\
C & 46 & 138 & 106 \\
D & 104 & 123 & 88 \\
E & 59 & 114 & 77 \\
F & 35 & 94 & 92 \\
G & 27 & 109 & 116 \\
All England \& Wales rural & 363 & 131 & 98 \\
\hline
\end{tabular}

Note: * Weighted averages of individual RDs.

Figure 3 shows the IMR trajectory of each of these clusters, Figure 4 the locations of the RDs of each cluster. To a striking degree, the RDs which we clustered for their statistical similarity also cluster spatially: Rural England and Wales had identifiable IMR zones. The strength of this finding confirms the value of using spatial modelling. To describe the zones a little further, cluster A had the highest 1850s IMR by some distance but it declines faster than average, so that while still above the 1900s mean it ceases to stand out so dramatically. Most cluster A districts are on low-lying arable land near the east coast: these are where Woods and Shelton found the early 19th-century socalled 'fenland' IMR penalty (Woods and Shelton 1997).

Cluster B's trajectory resembles A's. Again, the early IMR was very high, and in this case the decline is even faster. B was the only cluster to avoid the 1890 s reverse, usually attributed to the rise in diarrhoeal diseases over a series of hot dry summers (Woods 2000). Cluster B is concentrated in census regions South Midland and Eastern, and lies directly south of cluster A. 
Clusters $\mathrm{C}, \mathrm{D}$, and $\mathrm{E}$, in descending order of IMR, most resemble the central tendency of rural IMR for the whole of England and Wales, both in the level of their starting points and the slope of their IMR declines. C, with the poorest IMR performance of these three, lies directly west of A, with which its trajectory has a lot in common. Almost all its RDs are below average elevation, many of them in a major arable flood plain. Cluster D, the largest, with $104 \mathrm{RDs}$, has the greatest spatial dispersion, but large agglomerations of its RDs are found in census regions South Western and West Midlands, with significant outlying clumps in North Yorkshire, MidWales, and Eastern. D is the least homogeneous of the clusters by terrain and agriculture.

\section{Figure 3: IMR trajectories of the seven clusters}

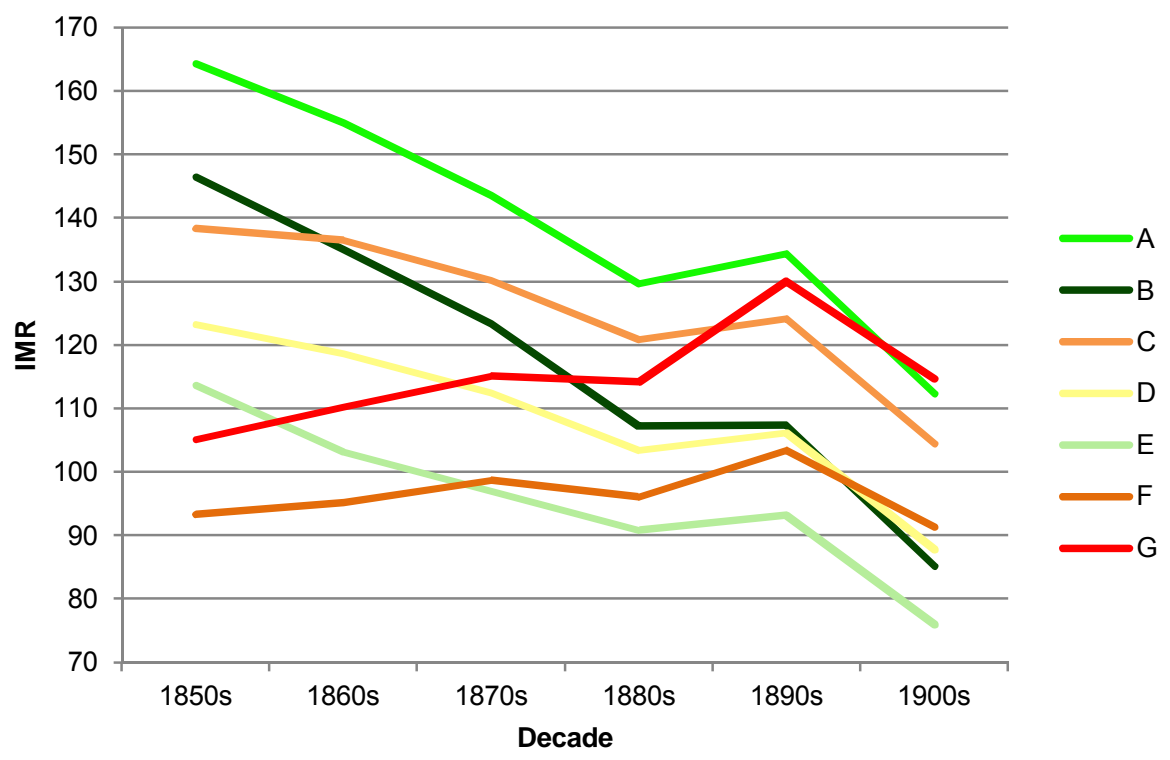

E, whose IMR trajectory is the best by some measure, and whose 1900s IMR is the lowest by some distance, has one of the tightest spatial concentrations. All but 2 of its 59 members lie south of Birmingham and a majority are grouped in a single continuous zone stretching north from the central part of England's south coast, characterised by well-drained low hills with mixed arable and pastoral agriculture. Cluster E is exciting in analytical terms: the causes of its exceptional IMR decline merit further work. 
Figure 4: Locations of RDs in the different clusters

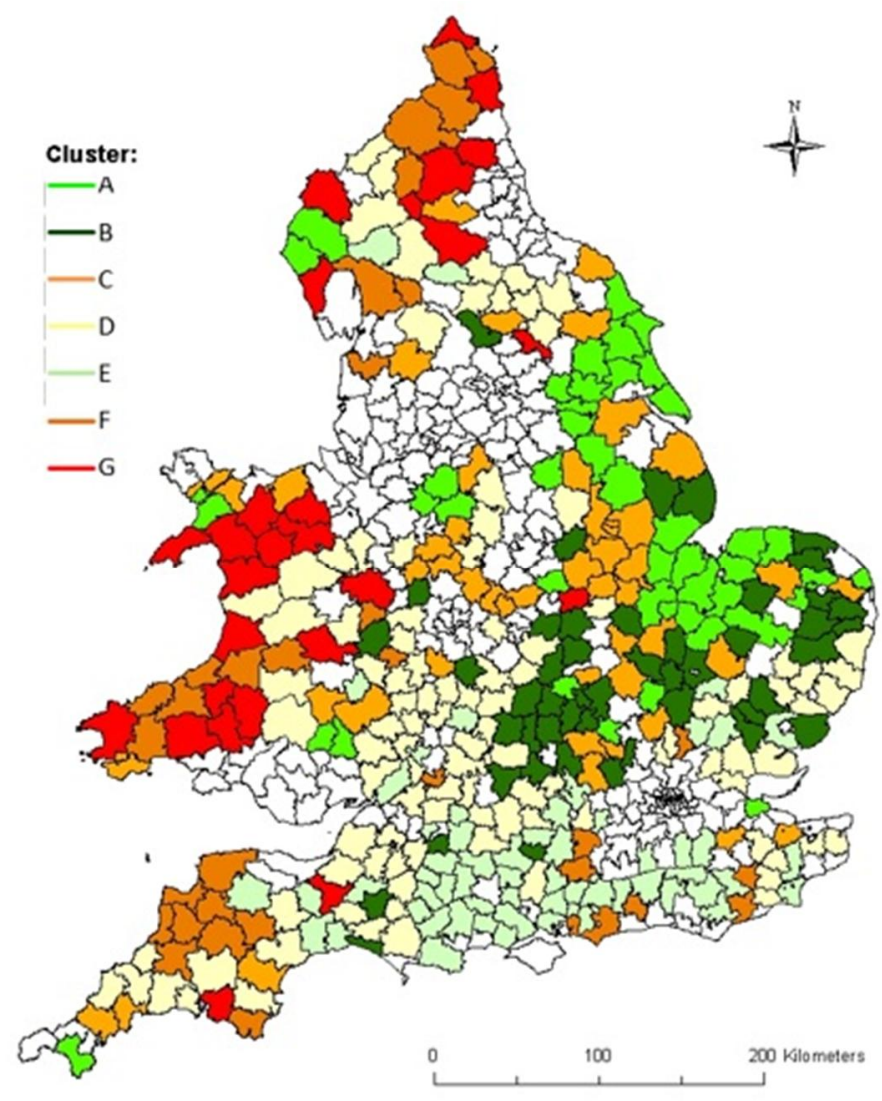

Note: Unshaded RDs were not classified as rural, or data was not available.

The final pair of clusters is distinctive for having rising IMR until the 1890s, while it was falling in the other clusters. Cluster F, which has the second-highest mean elevation of all clusters, started with the lowest 1850s IMRs but shows little improvement. Cluster $\mathrm{G}$ is the outlier, with the worst IMR performance and the highest mean elevation. Elevation meant that sheep farming played a much larger and arable a very much smaller role in these hilly or mountainous districts than elsewhere. We argue in a forthcoming Economic History Review article that this kind of pastoral agriculture preserved an $18^{\text {th }}$ century - and older - 'family economy' for longer than in the more capitalised farming of the arable zone, and that this family economy created a more 
equal sexual division of labour because it included more access to commons, more owner-occupiers and small tenants, and less dependence on wage labour away from home.

That social structure gave 1850 s mothers higher status and safeguarded their infants better than peers elsewhere. Thereafter, we think that the characteristics of places in clusters $\mathrm{F}$ and $\mathrm{G}$ hindered diffusion of the better approaches to infant care which were emerging by the 1900s, leading to rising IMR here. As for the question of which characteristics of these places did that, the existence of six cluster F RDs within $100 \mathrm{~km}$ of London - in the hill country of South Eastern region - hints that terrain, agriculture, or social structure may have been the key, rather than peripherality. There are parallels with the results of Thorvaldsen (2002) for Norway: like us, he found that the link between high IMR and high peripherality was only significant after the turn of the 20th century. There are also parallels with the work of Edvinsson, Garðarsdóttir, and Thorvaldsen (2008) for the Nordic countries as a whole: like us, they emphasise the diffusion of information as a factor making IMR decline more slowly in peripheral places. More work is needed to tease apart the relative contributions of peripherality, terrain, agriculture, social structure, and even (at least in the Nordic countries, where peripheral means Arctic), climate.

Figure 4 also permitted the discovery of groups of high-performing RDs from one cluster adjacent to very low-performing groups from another; for example, in Wales and in Northern region. This phenomenon also demands closer examination. What covariates, perhaps in terrain, climate, agriculture, or social structure, did these neighbours share, and which factors caused their diverging IMR outcomes? The stark contrasts evident on the map, for example in mid-Wales, are not an ecological fallacy produced by assigning mean cluster IMR performance to all its RDs. Using GIS to examine the detailed statistics spatially, $\mathrm{RD}$ by $\mathrm{RD}$, confirms that these 'cliff-edge' differences in IMR are real phenomena at RD level.

We do not wish to exaggerate the degree of spatial clustering and are content for Figure 4 to speak for itself. Furthermore, the possibility that variations in reporting accuracy between districts over time contributed to these patterns cannot be completely excluded (Higgs 1987). The clusters do have spatial outliers, but these are not problems to be explained away: they are examples of the complexity of the phenomena. For instance, Billesdon, adjoining Leicester, and Plympton St Mary, adjoining Plymouth, are outliers of cluster G (characterised by deteriorating IMR). Leicester and Plymouth were both towns of high IMR, so the deteriorating IMR in these two places could show the presence of urbanising fringes with poor living conditions.

Thus, latent trajectory analysis and the spatial analysis of the results reveal a set of rural IMR zones which, apart from the fenland area, were previously unknown. While the large number of places with statistically similar trajectories in Figure 4 which are 
adjacent, or very near each other, might be so by mere chance, the strength of their spatial clustering does strongly suggest a causal relationship between IMR and other phenomena showing a spatial pattern, such as agriculture type and rural social structure.

\section{Occupation}

We now turn to one such phenomenon. Both male and female occupation could be a strong influence on IMR: they may be thought of as mediating the impact of remoter, spatial factors stemming mainly from the geography of agriculture and sometimes that of mining and quarrying. The nature of this mediation had to be borne in mind when building a regression model (Allison 1999). To examine variations in occupation, we drew on the full individual-level census data in the Integrated Census Microdata (ICeM) digital resource in the UK Data Archive (Schürer and Higgs 2014). The I-CeM data captures the original Census Enumerator's Book entries and gives them a consistent coding, described in the online metadata. The correlations between IMR and the prevalence of different occupations at $\mathrm{RD}$ level were examined using the I-CeM occupation codes. Each data point is one RD. Numbers of workers in an age-sex combination in the occupational group of interest were compared to the total population of that age-sex combination to give occupation-specific employment rates. Age-bands used were 15 and over for males and, given our interest in maternal health, fertile age (15-44) for females.

While the census is by far the best large-scale source of occupation data it is by no means unproblematic, and the recording of female occupation is a particular issue (Horrell and Humphries 1995; Anderson 1999; Shaw-Taylor and Wrigley n.d.). While census data may capture full-time work reasonably, it is highly unlikely to record the range of part-time, makeshift, and informal activity (Jordan 1988). Husbands and enumerators, who normally decided what went into the Census Enumerators' Books on which I-CeM rests, and the clerks who compiled the Census Reports, held varying views on the definition of female work (Higgs 1996; Garrett 2007).

These interpretational problems are especially acute for women's agricultural work, where much activity, paid and unpaid, will have gone unrecorded. In the discussion which follows, it must be borne in mind that variation between RDs - or over time - in the proportion of women reported in a certain occupation could be artefacts of variation in reporting behaviour. When Verdon (2002) compared, for a small number of sites, census data on women working in agriculture with the evidence of the Agricultural Returns and even local farm records, she found evidence of substantial under-recording. Further work of this kind would be valuable. In addition to under-recording, women could also have been over-recorded as farmers' wives, a 
category meant to describe women participating in the husband's business, but open to use for all wives of farmers regardless of their economic activity. While in practice only a small minority of the wealthiest 19th-century English or Welsh farmers dispensed altogether with their wives' labour (Reay 2004), it is logically possible that the count of farmers' wives merely shows how many (married) farmers there were, revealing nothing about these women's work.

Both under- and over-reporting of female employment are, then, problems for those who wish to test the relationship between female employment and infant mortality in a materialist spirit. However, we take a more historicist approach to the relationship between the two. ${ }^{6}$ Certainly, employment could directly benefit the mother by giving her an income, or harm her via the occupational health hazards of which Victorian commentators made a great deal: either effect might predominate (Dyhouse 1978; Garrett and Reid 1994). And, given the mother's central place in the welfare of the young infant, what affected her affected her child (Williams and Galley 1995; Millward and Bell 2001). Maternal employment could also harm the infant if it forced the mother to use unsuitable forms of childcare such as inexperienced older siblings, or taking a young infant to the fields in bad weather (Sneddon 2006, Hinde and Fairhurst 2015).

But in addition to these objective influences, maternal employment had an indirect effect on infant welfare by raising the mother's subjective status within the household. As an independent earner and a person with her own social networks, she was in a better position to argue for more household resources to be allocated to her own welfare and that of her young child. The decision of a husband to tell the census enumerator that his wife had an occupation is itself an indicator that she had gained a certain status from her work, compared to the woman whose husband reported no occupation for her. In this historicist perspective, the text of the Census Enumerator's Book is no longer only a somewhat unreliable guide to a woman's occupation. Accordingly, we feel justified in discussing the relationship between census reports of female occupation and infant mortality.

We begin, however, with male occupations. We first test our hypothesis that the pastoral farming type of the north and west was more favourable to infant welfare than the arable. Occupation data allows this by identifying occupations such as shepherd, which are clear indicators of the pastoral agriculture type. Figure 5 presents the relationship between the proportion of shepherds in the male working population and IMR. (In principle we could study occupation without reference to gender, but in the strongly gendered labour markets of the 19th century this could obscure important

\footnotetext{
${ }^{6}$ For the distinction between materialist (or 'positivist') readings of a historical source (treating its statements as data which can be used unproblematically in present-day modes of thinking such as statistical analysis) and historicist readings (recognising that the meanings of its statements were created by their contemporary context, and need interpretation), see Carus and Ogilvie (2009).
} 
patterns in the data.) In the scatter plots which follow, the horizontal scales are logarithmic, to display the values bunched near zero more legibly.

Figure 5: IMR and percentage of shepherds in male population (1851, rural RDs)

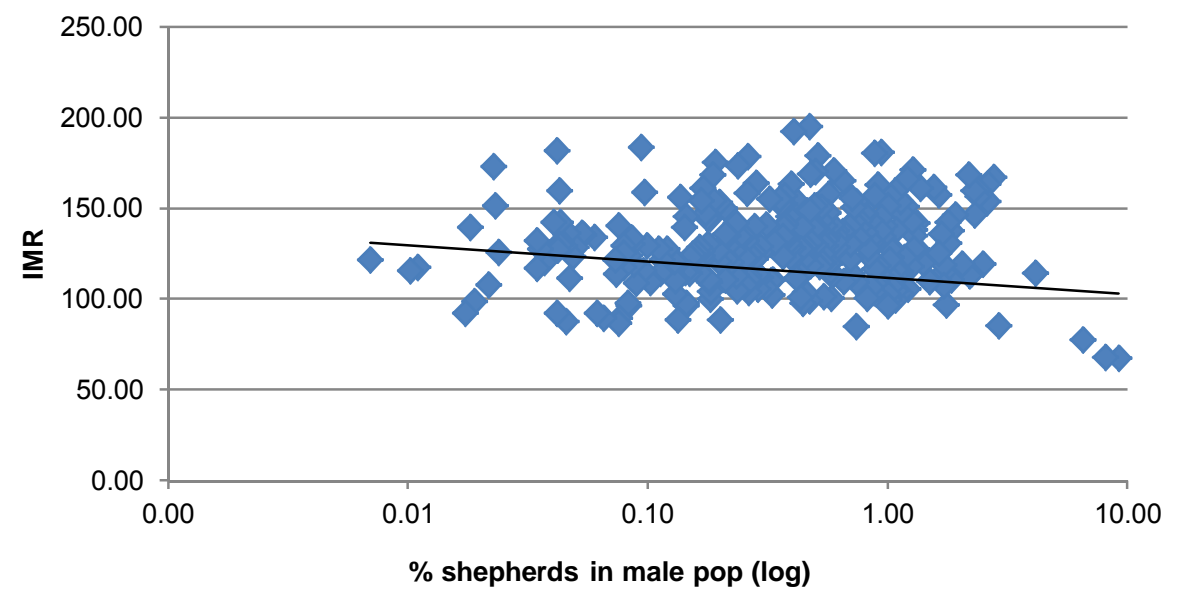

Source: I-CeM and GBHGIS.

It emerges that in 1851 the RDs where shepherds were most likely to occur were also those where the IMR was lower, though the effect was not a strong one. It persisted over time, becoming somewhat stronger by 1901 . This tends to confirm the benefits for infant welfare that we claimed for the pastoral economy compared to the arable.

The presence of concentrations of miners and quarrymen in a district was examined next. Reay (2004) correctly suggested that among rural as well as urban districts, industrial and mining locations were frequently the ones with high IMRs, though he admits places with little industry or mining could suffer similarly. However, he did not use any statistical tests of correlation: When we did, we found no significant correlation between these occupations and IMR. This was a surprising result because these groups, who had higher than average fertility and are said to have had poor communication between spouses (Szreter 1996), are often thought of as poorer than others at sharing resources within the household, which should have had an adverse effect on maternal health. Even in the twelve RDs where more than a fifth of men worked in mining and quarrying the IMR varied substantially. In 1851, for example, Crickhowell with $37 \%$ miners had an IMR of 173, while Reeth, with 54\% miners, had 
an IMR of only 118. Mining and quarrying did not in practice provide much of the explanation for higher IMRs in some rural RDs than others.

Turning to women, IMR correlated negatively (slope $=-0.8$ ) with the proportion of women of fertile age who reported any agricultural occupation: more farm work was associated with lower IMR. In aggregate, babies fared slightly better if the mother reported an agricultural occupation. This contradicts the contemporary view that maternal employment was bad for infant welfare (Dyhouse 1978).

This could, of course, have varied between occupations. To test whether the data allowed us to discriminate between beneficial and harmful kinds of farm work, subsets of occupation codes were examined. Of the twenty different agricultural occupations coded in I-CeM, women were concentrated in six. Two of these, combined in Figure 6, contained higher-status occupation categories: female farmers and graziers, and the female relatives of farmers who assisted in farm work ( $1851 \mathrm{~N}=40,705$ in our RDs).

Figure 6: IMR and percentage of female farmers in female population (1851, rural RDs)

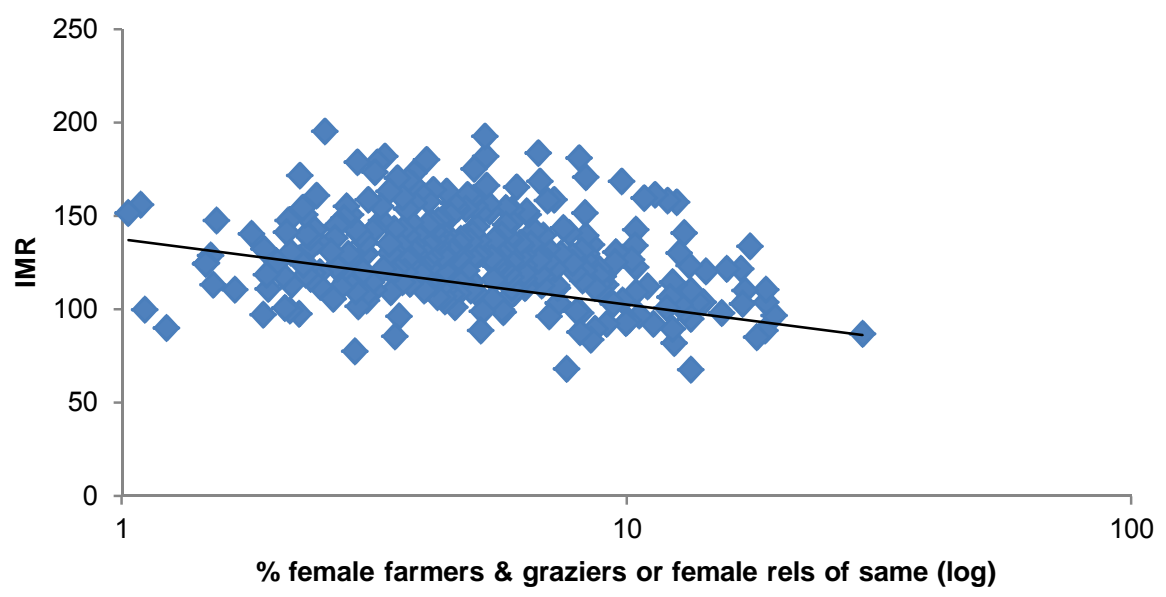

Source: I-CeM and GBHGIS.

Figure 6 shows that places where more women of fertile age were reported in the higher-status agricultural occupations had a slightly lower IMR. The four remaining occupation codes described work of lower-status, essentially farm labourers $(\mathrm{N}=28,356)$. Figure 7 illustrates the relationship between IMR and the presence of these labourers. 
Figure 7: IMR and percentage of female agricultural labourers in female population (1851, rural RDs)

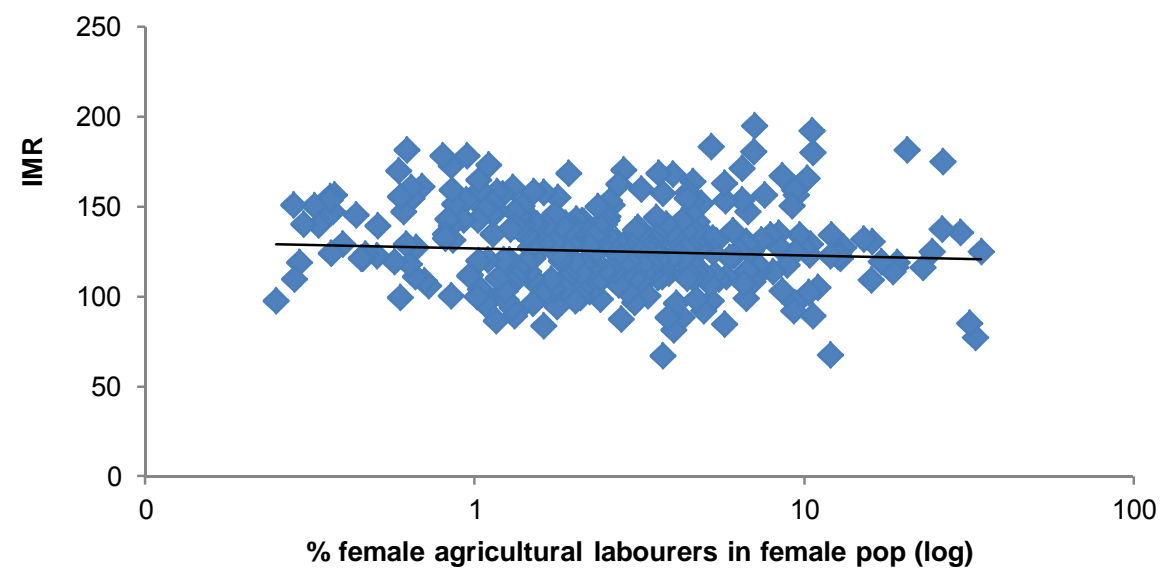

Source: I-CeM and GBHGIS.

The same relationship is observed as for the group of higher-status farmers' families, but it is weaker: here the slope $=-0.25$ compared to -1.8 in Figure 6 . So while work as an agricultural labourer also appears, in aggregate, to have been better for the IMR, for labourers the relationship was a more equivocal one. For all mothers, we have argued that having an occupation that the householder took seriously enough to report to the census conferred benefits on both mother and infant. However, all work was not equal, and for lower-status workers it looks as if some of the effects counteracted the benefits. For example, the physical demands of field work were greater than those on the farmer's wife, affecting nutritional status, and opportunities to organise childcare were more constrained.

In the regression results the Koenker test was statistically significant, indicating non-stationarity in this relationship; that is, spatial variation in the strength of the correlation between census occupation and IMR. This could have been, for example, because different types of agriculture, which were practised in different places, gave different tasks to women reporting the same occupation. Geographically Weighted Regression (GWR) (Fotheringham 2002; Matthews and Yang 2012) is a useful exploratory tool here, and was used to determine the spatial variation in the coefficient by which IMR varied with occupation. Our GWR followed a common-sense, exploratory specification in which we let the tool find the optimum bandwidth using Aikake's Information Criterion. Figure 8 illustrates the results for female agricultural 
labourers in 1851. Labourers are compared here, rather than farmers' wives, on the assumption that the nature of their employment varied with the type of agriculture practised more than that of farmers' wives did.

\section{Figure 8: Coefficients of the correlation between IMR and occupation: Female agricultural labourers, 1851}

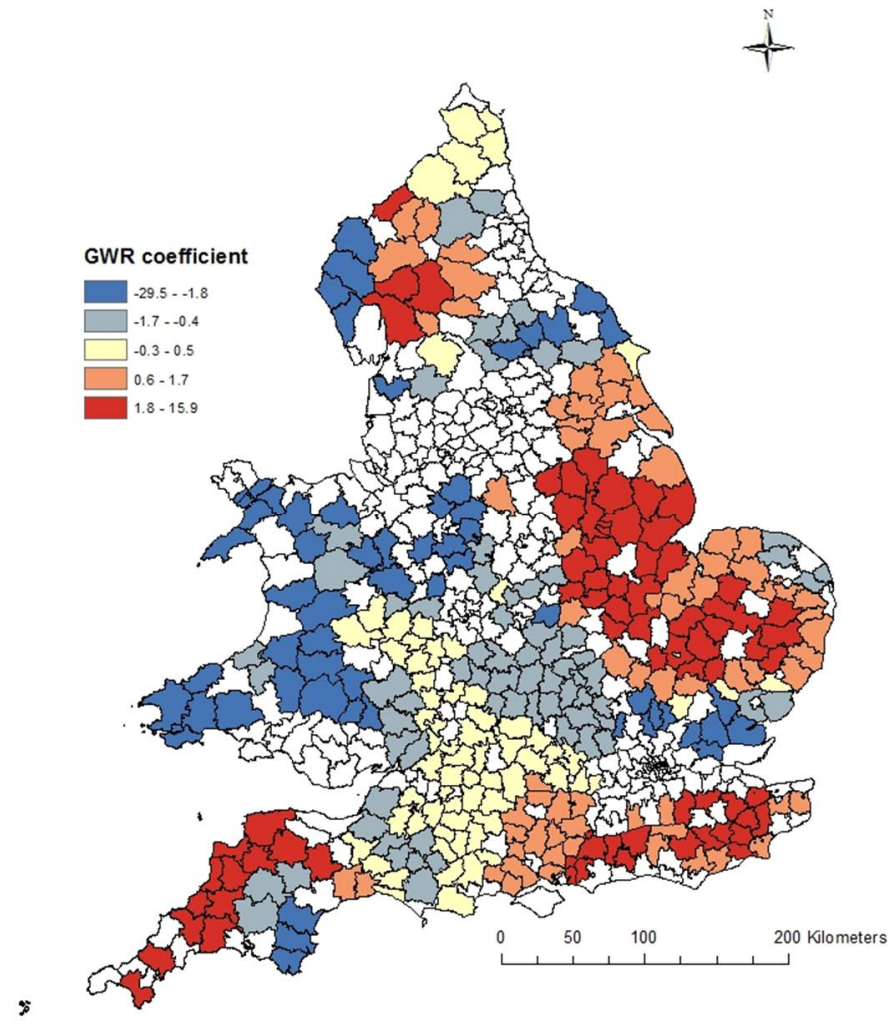

Note: Unshaded RDs were not classified as rural, or data were not available.

Figures 8 (1851) and 9 (1901) display the coefficients for the correlation of occupation with IMR in quintiles. The first quintile contains the places where the correlation was most negative (that is, where high occupation was associated with the lowest IMR), the last quintile the places where it was most positive. In Wales (mostly first quintile), we would interpret this as a sign that the nature of female work as an 
agricultural labourer was relatively beneficial for infant welfare. In much of eastern England, and also in Cornwall, higher levels of labouring employment were apparently harmful. This lends support to the views of Sneddon and of Hinde and Fairhurst that the particularly arduous nature of women's agricultural work in the east of England, such as weeding and picking vegetables, was what caused the harm (Sneddon 2006; Hinde and Fairhurst 2015).

Hinde and Fairhurst (2015) argue that infant care was more likely to be assigned to older siblings and other relatives when women worked in the labour-intensive vegetable-growing districts of eastern England than on "family-run farms in the north of England", and that this care was of a lower standard. It is instructive that our work based on occupation data provides support for these earlier conclusions, which were based on different socioeconomic and demographic variables. More support for the role of agriculture type in IMR comes from looking at the ten first-quintile RDs just north of London (Figure 8), where the market gardening sector, noted by Holderness (2000), provided less harmful forms of female agricultural employment than those available in cluster A.

In 1901, GWR again shows a geographical spread of coefficients, mostly similar to those in 1851 but with some differences (Figure 9). In particular, the correlations of female agricultural employment appear to have changed sign in various locations. However, too much should not be made of the 1901 data, since by 1901 the number of women in our rural districts reporting the occupation of agricultural labourer in the census had declined from the 1851 level of 28,000 to just under 6,000. Modern authorities agree that census under-reporting had worsened by this date (Higgs 1987). Our understanding of the relationship between IMR and different types of female employment would benefit from more local studies like those of Sneddon and Hinde and Fairhurst, in which information about local agricultural and social conditions is combined with demographic data. 


\section{Figure 9: Coefficients of the correlation between IMR and occupation: Female} agricultural labourers, 1901

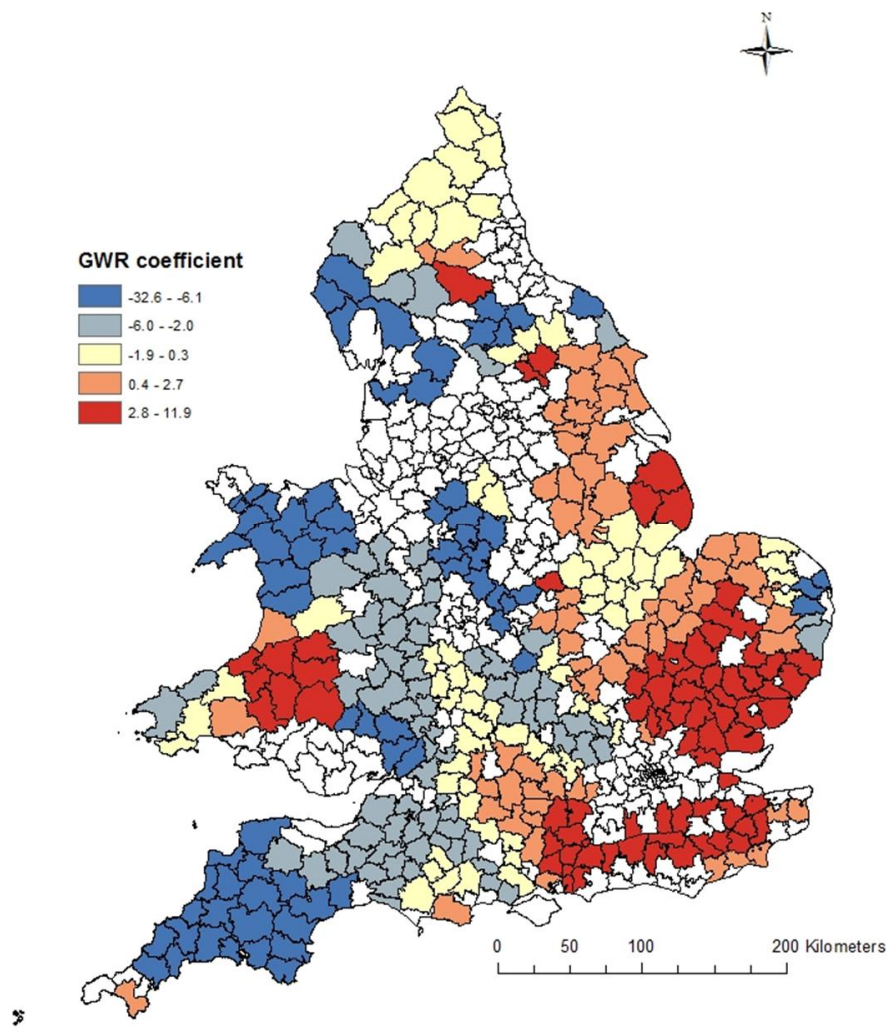

Note: Unshaded RDs were not classified as rural, or data were not available.

Contemporaries certainly thought that female agricultural employment had declined, particularly in the south and east (Dewey 2000), and this view is supported by Verdon's substantial research in noncensus sources (2002). We argue that the concentration of this decline in the eastern regions, where we have concluded that female agricultural work made the IMR worse, favoured the faster decline of IMR in the south and east, noted in the first part of this paper. 


\section{Conclusion}

We have shown by latent trajectory analysis and spatial representation of the results that rural England and Wales were divided into a set of IMR zones which, apart from the A area, were previously unknown. Our forthcoming Economic History Review article examines some of the socioeconomic phenomena which could have generated these spatial patterns of IMR over the later 19th century. The discovery of these IMR patterns should also prompt more local studies.

Meanwhile, here we present results about one of the correlates of IMR: occupation. The evidence from geographically weighted regression that female farm work could have reduced infant survival chances in the south and east but benefitted infant survival chances in much of the north and west (Figure 8) is new and significant. It offers one good reason why IMR should have declined faster in the south and east, and declined slower (or even increased) in the north and west. The decline in female agricultural employment after 1851 seems to have helped to remove a source of harm in the arable economy of the south and east, while at the same time removing a source of benefit in the upland, pastoral parts of the country.

\section{Acknowledgements}

The research leading to these results has received funding from the European Research Council (ERC) under the European Union's Seventh Framework Programme (FP7/2007-2013) / ERC grant "Spatial Humanities: Texts, GIS, places" (agreement number 283850). We wish to thank participants in seminars at the Local Population Studies Society and the British Society for Population Studies, the International Union for the Scientific Study of Population seminar on Spatial Analysis in Historical Demography, and the anonymous referees, for their helpful advice and comments. Kay Eastaugh of the UK Data Archive deserves special thanks for her assistance with the ICeM data. 


\section{References}

Allison, P. (1999). Multiple regression: A primer. Thousand Oaks: Sage.

Anderson, M. (1999). What can the mid-Victorian censuses tell us about variations in married women's employment? Local Population Studies 62(4): 9-30.

Atkinson, P.D., Francis, B.J., Gregory, I.N., and Porter, C. (forthcoming). Patterns of infant mortality in rural England and Wales, 1850-1910. Economic History Review.

Bengtsson, T. and Dribe, M. (2010). Quantifying the family frailty effect in infant and child mortality by using median hazard ratio (MHR): The case of rural Sweden, 1766-1895. Historical Methods 43(1): 15-27. doi:10.1080/01615440903 270299.

Brandström, A., Edvinsson, S., and Rogers, J. (2000). Infant mortality in Sweden. Historical Methods 33(2): 105-114. doi:10.1080/01615440009598953.

Carus, A.W. and Ogilvie, S. (2009). Turning qualitative into quantitative evidence: A well-used method made explicit. Economic History Review 62(4): 893-925. doi:10.1111/j.1468-0289.2009.00486.x.

Dewey, P. (2000). Farm labour. In: Collins, E.J.T. (ed.). The agrarian history of England and Wales, vol. vii, 1850-1914. Cambridge: Cambridge University Press: $810-862$.

Dobson, M. (1997). Contours of death and disease in early modern England. Cambridge: Cambridge University Press. doi:10.1017/CBO9780511581847.

Dyhouse, C. (1978). Working class mothers and infant mortality in England, 1895-1914. Journal of Social History 12(2): 248-267. doi:10.1353/jsh/12.2.248.

Edvinsson, S., Garðarsdóttir, O., and Thorvaldsen (2008) Infant mortality in the Nordic countries, 1780-1930. Continuity and Change 23(3): 457-485. doi:10.1017/ s0268416008006917.

Fotheringham, A.S. (2002). Geographically weighted regression: The analysis of spatially varying relationships. Chichester and Hoboken: Wiley.

Garrett, E. and Reid, A. (1994). Satanic mills, pleasant lands: Spatial variation in women's work, fertility and infant mortality as viewed from the 1911 census. Historical Research 67(163): 156-177. doi:10.1111/j.1468-2281.1994.tb01 822.x. 
Garrett, E. (2007). The dawning of a new era? Women's work in England and Wales at the turn of the twentieth century. In: Goose, N. (ed.). Women's work in industrial England. Hatfield: Local Population Studies Society: 314-362.

Gatley, D. (1997). Computerising the 1861 census abstracts and vital registration statistics. Local Population Studies 58: 37-47.

Gregory, I., Bennett, C., Gilham, V.L., and Southall, H. (2002). The Great Britain historical GIS: From maps to changing human geography. The Cartographic Journal 39(1): 37-49. doi:10.1179/caj.2002.39.1.37.

Gregory, I. (2008). Different places, different stories: Infant mortality decline in England and Wales, 1851-1911. Annals of the Association of American Geographers 98(4): 773-794. doi:10.1080/00045600802224406.

Higgs, E. (1987). Women, occupations and work in the nineteenth century censuses. History Workshop Journal 23(1): 59-80. doi:10.1093/hwj/23.1.59.

Higgs, E. (1996). The tabulation of occupations in the nineteenth-century census, with special reference to domestic servants. In: Mills, D. and Schürer, K. (eds). Local communities in the Victorian census enumerators books. Oxford: Leopard's Head Press: 27-35.

Hinde, P.R.A. and Fairhurst, V. (2015). Why was infant mortality so high in eastern England in the mid nineteenth century? Local Population Studies 94(1): 48-66.

Holderness, B.A. (2000). Specialised cropping systems. In: Collins, E.J.T. (ed.). The agrarian history of England and Wales, vol. vii, 1850-1914. Cambridge: Cambridge University Press: 479-486.

Horrell, S. and Humphries, J. (1995). Women's labour force participation and the transition to the male-breadwinner family, 1790-1865. Economic History Review 48(1): 89-117. doi:10.2307/2597872.

Jordan, E. (1988). Female unemployment in England and Wales, 1851-1911: An examination of the census figures for 15-19-year-olds. Social History 13(2): 175-190. doi:10.1080/03071028808567709.

Lee, C. (1991). Regional inequalities in infant mortality in Britain, 1861-1971: Patterns and hypotheses. Population Studies 45(1): 55-65. doi:10.1080/003247203 1000145086.

Matthews, S.A. and Yang, T.-C. (2012) Mapping the results of local statistics: Using geographically weighted regression. Demographic Research 26(6): 151-166. doi:10.4054/demres.2012.26.6. 
Millward, R. and Bell, F. (2001). Infant mortality in Victorian Britain: The mother as medium. Economic History Review 54(4): 699-733. doi:10.1111/1468-0289. 00209 .

Nagin, D.S. (1999). Analyzing developmental trajectories: A semi-parametric, groupbased approach. Psychological Methods 4(2): 139-157. doi:10.1037/1082-989X. 4.2.139.

Perelli-Harris, B. and Lyons-Amos, M. (2015). Changes in partnership patterns across the life course: An examination of 14 countries in Europe and the United States. Demographic Research 33(6): 145-178. doi:10.4054/DemRes.2015.33.6.

Reay, B. (2004). Rural Englands: Labouring lives in the nineteenth century. Basingstoke: Palgrave Macmillan.

Schürer, K. and Higgs, E. (2014). Integrated Census Microdata (I-CeM): 1851-1911. [data collection]. UK Data Service. SN: 7481. doi:10.5255/UKDA-SN-7481-1.

Shaw-Taylor, L. and Wrigley, E.A. (n.d.). Diverse experiences: The geography of adult female employment in England and the 1851 census. www.geog.cam.ac.uk/ research/projects/occupations/abstracts/paper12.pdf.

Short, B. (2000). Rural demography, 1850-1914. In: Collins, E.J.T. (ed.). The agrarian history of England and Wales, vol. vii, 1850-1914. Cambridge: Cambridge University Press: $1232-1296$.

Sneddon, S. (2006). A double penalty? Infant mortality in the Lincolnshire Fens, 1870-1900. In: Garrett, E., Galley, C., Shelton, N., and Woods, R. (eds.). Infant mortality: A continuing social problem. Aldershot: Ashgate: 79-98.

Southall, H., Gilbert, D., and Gregory, I. (1998). Great Britain historical database: Census statistics, demography, 1841-1931 [data collection]. UK Data Service [distributor]. SN: 3707. doi:10.5255/UKDA-SN-3707-1.

Sturgis, P. and Sullivan, L. (2008). Exploring social mobility with latent trajectory groups. Journal of the Royal Statistical Society 171(1): 65-88. doi:10.1111/j. 1467-985X.2007.00516.x.

Szreter, S. (1991). The GRO and the public-health movement in Britain, 1837-1914. Social History of Medicine 4(3): 435-463. doi:10.1093/shm/4.3.435.

Szreter, S. (1996). Fertilty, class and gender in Britain, 1860-1940. Cambridge: Cambridge University Press. 
Szreter, S. and Hardy, A. (2000). Urban fertility and mortality patterns. In: Daunton, M. (ed.). The Cambridge urban history of Britain. Cambridge: Cambridge University Press: 629-672.

Thorvaldsen, G. (2002). Rural infant mortality in nineteenth-century Norway. Hygiea Internationalis 3(1): 75-113. doi:10.3384/hygiea.1403-8668.023175.

Verdon, N. (2002). Rural women workers in nineteenth century England: Gender, work and wages. Woodbridge: Boydell and Brewer.

Williams, N. and Galley, C. (1995). Urban-rural differentials in infant-mortality in Victorian England. Population Studies 49(3): 401-420. doi:10.1080/00324720 31000148746.

Woods, R. and Hinde, P.R.A. (1987). Mortality in Victorian England: Models and patterns. The Journal of Interdisciplinary History 18(1): 27-54. doi:10.2307/ 204727.

Woods, R., Watterson, P., and Woodward, J. (1989). The causes of rapid infant mortality decline in England and Wales, 1861-1921, Part 2. Population Studies 43(1): 113-132. doi:10.1080/0032472031000143876.

Woods, R. and Shelton, N. (1997). An atlas of Victorian mortality. Liverpool: Liverpool University Press.

Woods, R. (2000). The demography of Victorian England and Wales. Cambridge: Cambridge University Press. doi:10.1017/CBO9780511496127. 
Atkinson et al:: Spatial modelling of rural infant mortality and occupation in nineteenth-century Britain 